\title{
Properties of the main trough of the $F$ region derived from Dynamic Explorer 2 data
}

\author{
Erika Feichter and Reinhart Leitinger \\ Institut für Geophysik, Astrophysik und Meteorologie, Karl-Franzens-Universität Graz, Austria
}

\begin{abstract}
In winter and equinoctial season nights, the main trough of the $F$ region is an important stable structure of the ionosphere at the border between mid and high latitudes. Therefore it has to be taken into account in modelling and mapping approaches. Werner and Prölss (1995) derived a model for the position of the trough minimum which has found wide acceptance. The model is based on in-situ electron density data measured aboard the low orbiting Dynamic Explorer satellite DE 2 (1981-1986). We present results for other properties of the main trough derived from the same data set. These results are sufficiently good for modelling purposes which need reliable information on the depth, the equatorward and poleward width and the steepness of the walls of the trough. Because of the eccentric orbit of DE 2 (orbit height between about 300-1000 km) it was necessary to «project» observed electron densities to the peak of the $F_{2}$ layer. This was done by means of the electron density model COSTprof. The database was restricted to those cases for which the height of DE 2 was below $700 \mathrm{~km}$. Examples are shown for «typical» troughs observed under various conditions.
\end{abstract}

Key words ionospheric F region - main trough model - Dynamic Explorer data - trough shape parameters - trough minimum model

\section{Introduction}

Our trough studies are based on data gained by the satellite Dynamic Explorer DE 2 from 1981 to 1983 . The altitude of its orbit was between about 300 and $1000 \mathrm{~km}$ (perigee: 309 $\mathrm{km}$, apogee $1012 \mathrm{~km}$, inclination: $89.99^{\circ}$, period: 98 min).

The two satellites DE 1 and DE 2 became operational in 1981 . The nearly polar and nearly coplanar orbits provided the unique capability

Mailing address: Dr. Reinhart Leitinger, Institute for Geophysics, Astrophysics and Meteorology, KarlFranzens-Universität Graz, Universitätsplatz 5, 8010 Graz, Austria; e-mail: reinhart.leitinger@uni-graz.at of acquiring data at two altitudes along common magnetic flux tubes. Data acquisition during passages of the spacecraft through specific geophysical regions like the dayside cusp and plasmapause were emphasised. The general objective point of the mission was the investigation of magnetosphere-ionosphereatmosphere coupling processes.

From the DE 2 data we first eliminated data from altitudes above $700 \mathrm{~km}$ to avoid «plasmaspheric» trough observations and investigated the Northern Hemisphere exclusively.

Additionally we compared published models of the variation of the latitudinal location of the trough minimum and decided on the use of the trough minimum model of Werner and Prölss (1995). Other models have been published, e.g., that of Annakuliev et al. (1997).

S. Werner created two empirical models basing on electron density data. For the time dependence he used Magnetic Local Time (MLT) values and for the coordinates of the location of the minimum polar invariant latitude. He divided 
the time into 10 min intervals and calculated the median of each data set. In model A he fitted a Fourier series approximation (degree 2) to the medians. Model B also includes a distinction between two possible trough locations between 3 and 9 MLT (a «new» trough at high polar cap latitudes and the «old» trough at a much more equatorward position). Model B shows the time dependence of the minimum as an Archimedian spiral (degree 3).

Werner and Prölss (1995) also investigated the dependence of the trough minimum position of magnetic activity and seasons because the trough position moves towards lower latitudes during disturbed conditions and will also be influenced by the seasons. The models neglect as insignificant the influence of solar activity (Putz and Leitinger, 1987, 1988).

In 1999 we investigated the usefulness of published models of the $F$-region trough.

The $F$-region trough is a stable structure that occurs above all during winter and equinoctial months especially during the night. We can interpret the ionisation minimum of the trough as the border between «middle» and «high» latitudes. The high variability of the ionisation poleward of the trough minimum has consequences for modelling: it is not sufficient to use solar activity parameters as input but one has to add information on geomagnetic activity, too. This means, strictly speaking, that one has to leave the realm of pure monthly average models. The position of the trough is influenced by the ionospheric conditions at higher latitudes which depend on solar-terrestrial relations via the solar wind, the interplanetary magnetic field, and the reaction of the magnetosphere. Cross polar cap plasma convection and precipitation of energetic particles play a major role in trough formation, movement and maintenance.

Since the latitudinal range of the trough is small it does not show in large scale empirical models. Therefore we assume that a separate trough model is combined with a large scale model by multiplication:

$$
\boldsymbol{M}(h, \varphi, \lambda)=\boldsymbol{L}(h, \varphi, \lambda) \boldsymbol{T}(h, \varphi, \lambda)
$$

(M: resulting model, $\boldsymbol{L}$ : large scale model, $\boldsymbol{T}$ : trough model; $h$ : height, $\varphi$ : geographic latitude, $\lambda$ : geographic longitude).

\section{Preparation of DE 2 data and trough examples}

Werner and Prölss have used the DE 2 electron density data directly to derive their trough minimum model. For any other parameter of the trough this is not possible because of the change in orbit height. To gain comparable conditions we kept to DE 2 heights below 700 $\mathrm{km}$ and we have «projected» the electron densities to the peak of the $F_{2}$ layer. This was done by means of the electron density model COSTprof (Leitinger et al., 2001)

$$
\begin{gathered}
N_{m}(\mathrm{DE} 2)= \\
N_{e}(\mathrm{DE} 2) N_{m}(\mathrm{COST} \text { prof }) / N_{e}(\mathrm{COSTprof})
\end{gathered}
$$

$N_{m}$ (DE 2): inferred peak electron density; $N_{e}(\mathrm{DE} 2)$ : measured in-situ electron density; $N_{m}($ COSTprof $)$ : peak electron density from COSTprof for the latitude and longitude of DE 2;

$N_{e}$ (COSTprof): electron density from COSTprof for the position of DE 2.

The «trough parameters» depth, half width (equatorward, poleward, total), steepness of the walls were gained in the following way:

1) The projected electron densities were low pass filtered.

2) The intersection points (E equatorward, $P$ poleward) of the filter results with the unfiltered curve were used to define the borders of the trough.

3) The trough minimum (M) was found in the unfiltered projected electron densities.

Some trough examples are shown in fig. 1: peak electron density (gained by «projection») versus invariant latitude. DE 2 orbit parameters for the trough minimum are found in the headers and foot lines of each graphic. The trough properties derived in the indicated way are found on top of each panel. 

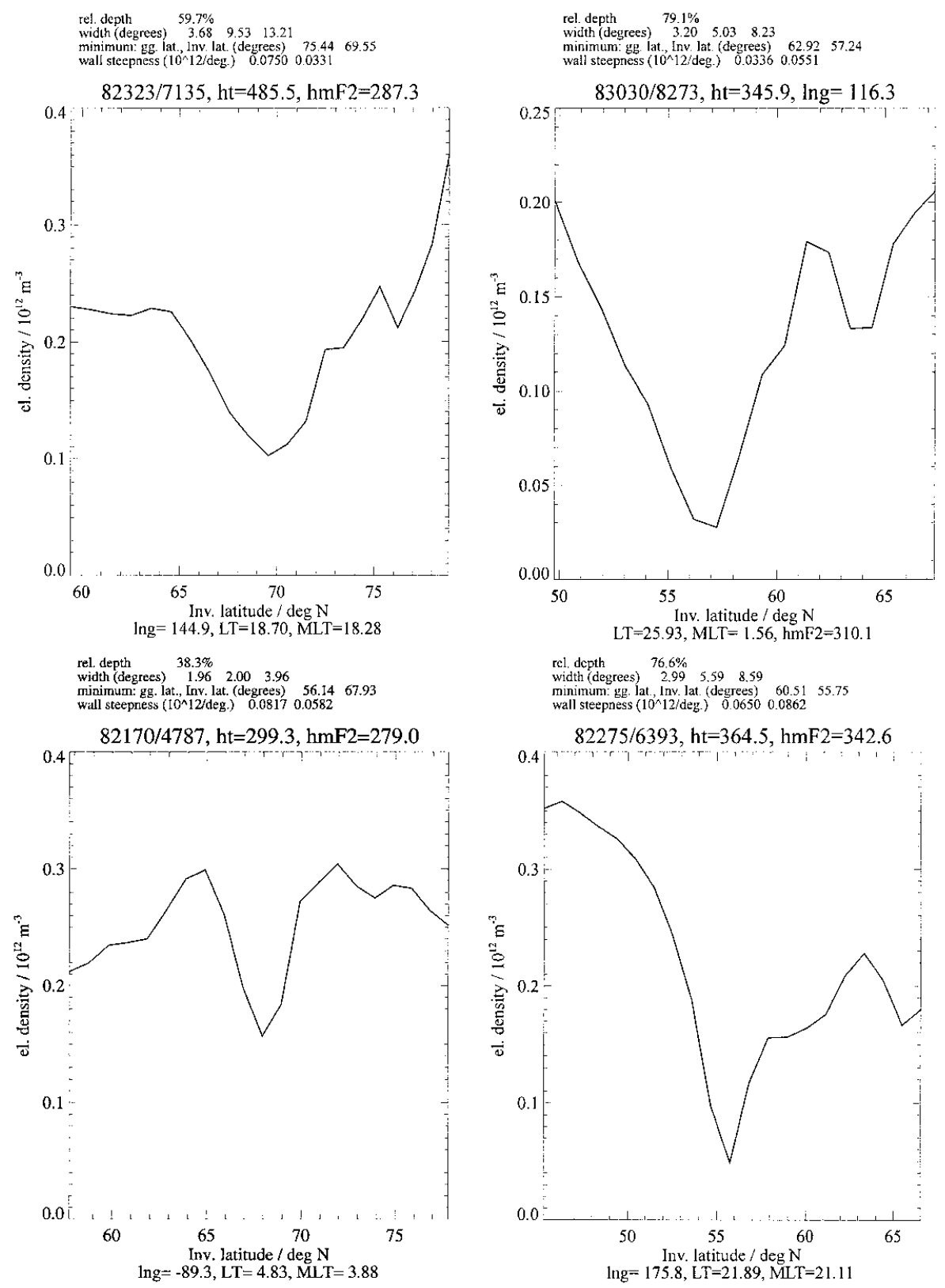

Fig. 1. Examples for DE 2 troughs, projected to the $F_{2}$ peak. Top: winter conditions; bottom left: summer conditions; bottom right: equinox conditions. Peak electron density in units of $10^{12} \mathrm{~m}^{-3}$ versus invariant latitude $\left({ }^{\circ} \mathrm{N}\right)$. Header and foot line information: date (year and day number) / orbit number; ht: satellite height; $h_{m} F_{2}$ : height of the $F_{2}$ peak; lng: geogr. longitude; LT: local time; MLT: magnetic local time. The «trough parameters» are listed above the panels (left: equatorward; right: poleward; «width»: half width, third value is total half width). 
Table I. Trough parameter statistics based on all available DE 2 data (years 1981-1983). L: lower quartile; M: median; U: upper quartile; MLT: magnetic local time; (e): equatorwards; (p) polewards.

\begin{tabular}{|c|c|c|c|c|c|c|c|}
\hline \multicolumn{8}{|l|}{ (1) All seasons } \\
\hline & \multicolumn{3}{|c|}{ Day (08-18 MLT) } & \multicolumn{3}{|c|}{ Night (18-08 MLT) } & \\
\hline & $\mathrm{L}$ & M & $\bar{U}$ & $\mathrm{~L}$ & M & $\mathrm{U}$ & \\
\hline Rel. depth & 37.8 & 50.5 & 63.3 & 41.3 & 56.2 & 67.7 & percent \\
\hline Half width (e) & 2.6 & 4.1 & 5.8 & 2.9 & 4.6 & 6.3 & degrees \\
\hline Half width (p) & 2.1 & 3.5 & 5.2 & 2.4 & 3.4 & 5.3 & degrees \\
\hline Total width & 5.6 & 8.0 & 9.6 & 6.7 & 8.4 & 10.3 & degrees \\
\hline Rel. steepness (e) & 0.28 & 0.41 & 0.78 & 0.19 & 0.39 & 0.91 & 1/degree \\
\hline Rel. steepness (p) & 0.28 & 0.52 & 0.91 & 0.37 & 0.60 & 1.08 & 1/degree \\
\hline
\end{tabular}

Total number of troughs read in: 1779

Troughs with relative depth $>20 \%$, height of satellite $<700.0 \mathrm{~km}$ and total width $<20.0: 506$ Day: 488, night: 1116

(2) Winter

\begin{tabular}{|c|c|c|c|c|c|c|c|}
\hline & \multicolumn{3}{|c|}{ Day (08-18 MLT) } & \multicolumn{3}{|c|}{ Night (18-08 MLT) } & \\
\hline & $\mathrm{L}$ & M & $\mathrm{U}$ & $\mathrm{L}$ & $\mathrm{M}$ & $\mathrm{U}$ & \\
\hline Rel. depth & 42.4 & 56.1 & 66.6 & 45.7 & 59.4 & 69.4 & percent \\
\hline Half width (e) & 2.8 & 4.1 & 5.9 & 3.6 & 5.3 & 6.8 & degrees \\
\hline Half width (p) & 2.0 & 3.3 & 5.1 & 2.3 & 3.3 & 5.0 & degrees \\
\hline Total width & 5.4 & 8.0 & 9.5 & 7.3 & 8.8 & 10.5 & degrees \\
\hline Rel. steepness (e) & 0.29 & 0.40 & 0.73 & 0.17 & 0.32 & 0.74 & 1/degree \\
\hline Rel. steepness (p) & 0.31 & 0.61 & 0.93 & 0.41 & 0.65 & 1.22 & 1/degree \\
\hline
\end{tabular}

Total number of troughs read in: 1128

Troughs with relative depth $>20 \%$, height of satellite $<700.0 \mathrm{~km}$ and total width $<20.0: 957$

Day: 328, night: 709

\section{(3) Equinoctial months}

\begin{tabular}{|c|c|c|c|c|c|c|c|}
\hline & \multicolumn{3}{|c|}{ Day (08-18 MLT) } & \multicolumn{3}{|c|}{ Night (18-08 MLT) } & \\
\hline & $\mathrm{L}$ & $\mathrm{M}$ & $\bar{U}$ & $\mathrm{~L}$ & $\mathrm{M}$ & $\mathrm{U}$ & \\
\hline Rel. depth & 33.1 & 44.6 & 54.8 & 36.6 & 52.7 & 65.3 & percent \\
\hline Half width (e) & 2.2 & 3.7 & 5.6 & 2.4 & 3.7 & 5.2 & degrees \\
\hline Half width (p) & 2.1 & 4.0 & 5.3 & 2.4 & 3.8 & 5.9 & degrees \\
\hline Total width & 5.8 & 8.0 & 9.9 & 6.3 & 7.8 & 9.7 & degrees \\
\hline Rel. steepness (e) & 0.25 & 0.43 & 0.82 & 0.25 & 0.52 & 1.05 & 1/degree \\
\hline Rel. steepness (p) & 0.23 & 0.40 & 0.76 & 0.29 & 0.51 & 0.91 & 1/degree \\
\hline
\end{tabular}

Total number of troughs read in: 547

Troughs with relative depth $>20 \%$, height of satellite $<700.0 \mathrm{~km}$ and total width $<20.0: 476$

Day: 134, night: 351

\section{(4) Summer}

\begin{tabular}{|c|c|c|c|c|c|c|c|}
\hline & \multicolumn{3}{|c|}{ Day (04-20 MLT) } & \multicolumn{3}{|c|}{ Night (20-04 MLT) } & \\
\hline & $\mathrm{L}$ & M & $\mathrm{U}$ & $\mathrm{L}$ & M & $\mathrm{U}$ & \\
\hline Rel. depth & 27.6 & 35.1 & 44.5 & 34.2 & 38.3 & 46.5 & percent \\
\hline Half width (e) & 2.4 & 4.2 & 5.3 & 1.6 & 2.2 & 3.3 & degrees \\
\hline Half width (p) & 2.7 & 3.7 & 5.7 & 1.9 & 3.1 & 5.1 & degrees \\
\hline Total width & 6.6 & 8.2 & 9.8 & 4.2 & 6.3 & 7.7 & degrees \\
\hline Rel. steepness (e) & 0.22 & 0.42 & 1.48 & 1.05 & 1.37 & 1.91 & 1/degree \\
\hline Rel. steepness (p) & 0.19 & 0.55 & 0.95 & 0.45 & 0.62 & 0.93 & 1/degree \\
\hline
\end{tabular}

Total number of troughs read in: 104

Troughs with relative depth $>20 \%$, height of satellite $<700.0 \mathrm{~km}$ and total width $<20.0: 73$

Day: 46, night: 29 
Dynamics Explorer 2 data, trough statistics 1981-1983

1128 Winter troughs for orbit heights $<700 \mathrm{~km}$, minimum rel. depth $20 \%$, maximal width 20 degrees. hatched: interquartile range
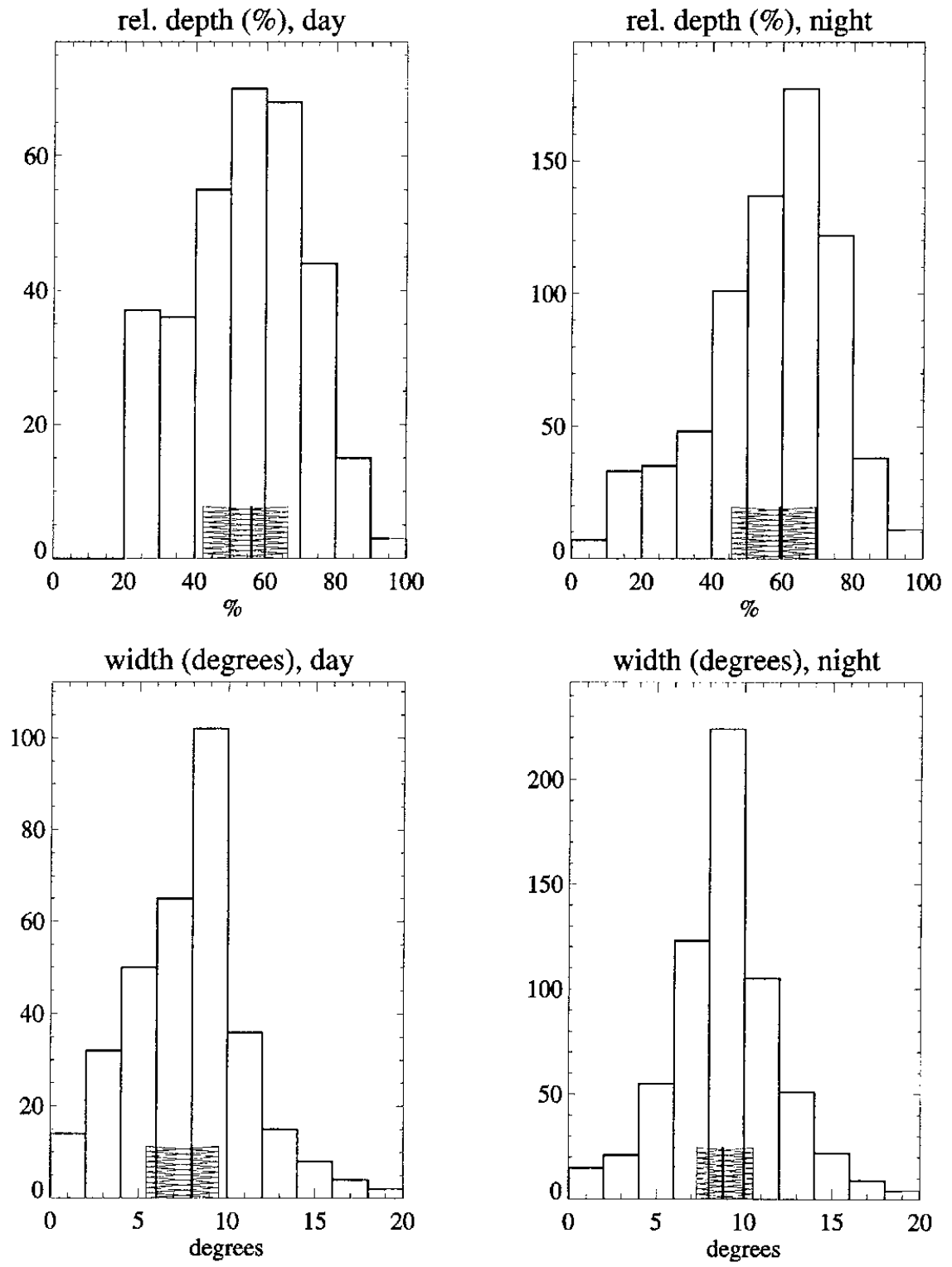

Fig. 2. Histograms for the relative depth and the total half width of the trough under Winter conditions. Left hand side: daytime (08-18 MLT); right hand side: nighttime (18-08 MLT). 

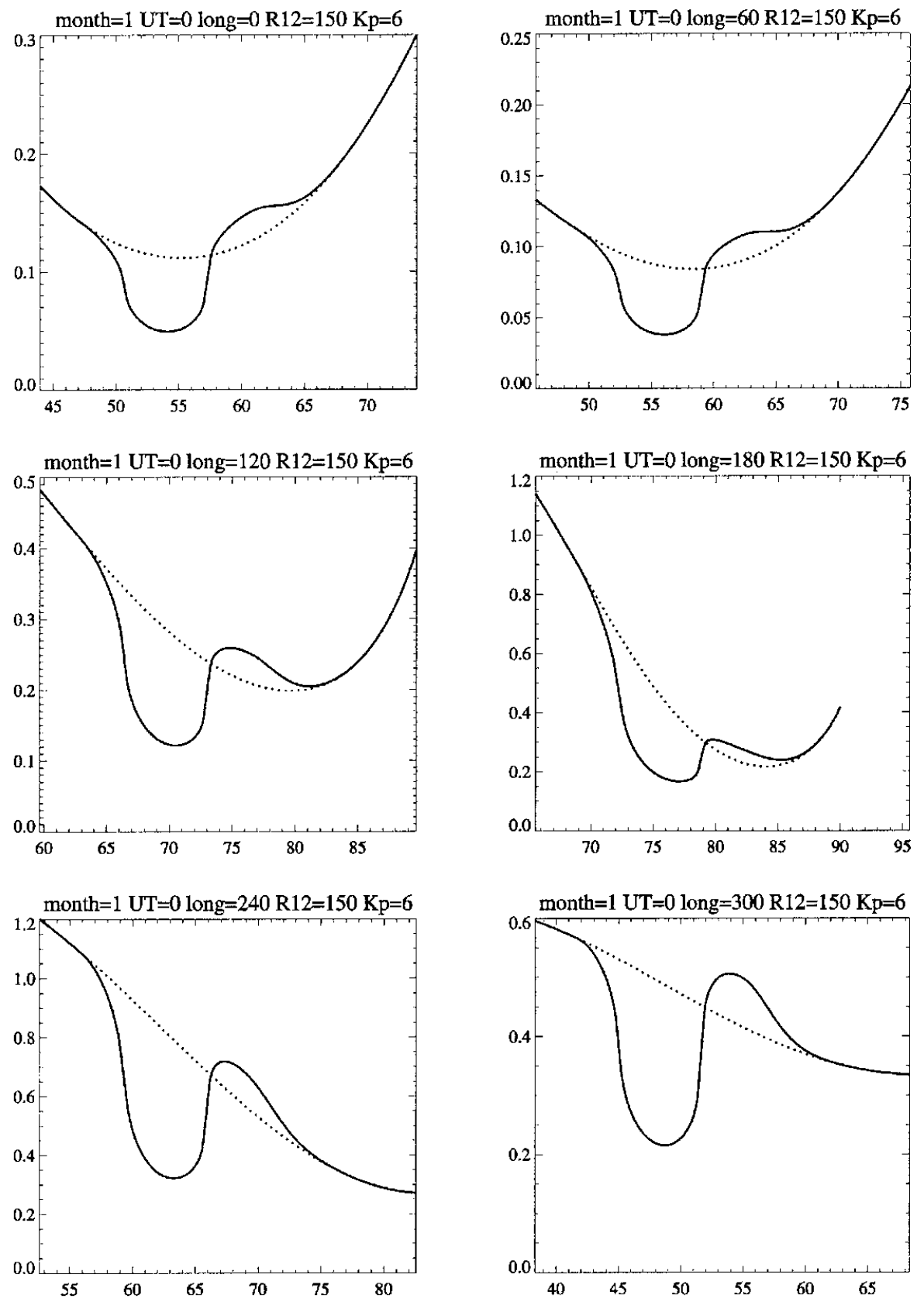

Fig. 3. Examples for the shape of the model trough: trough combined with peak electron density from the ITU-R (CCIR) coefficients (solid lines). Dotted: without trough modulation. Winter (January), nighttime (UT $=0 \mathrm{~h}$ ), high solar activity $\left(R_{12}=150\right)$, high level of geomagnetic activity $\left(K_{p}=6\right)$. Peak electron density in units of $10^{12} \mathrm{~m}^{-3}$ versus geogr. latitude $\left({ }^{\circ} \mathrm{N}\right)$, geographic longitudes: $0^{\circ} \mathrm{E}, 60^{\circ} \mathrm{E}, 120^{\circ} \mathrm{E}, 180^{\circ} \mathrm{E}, 240^{\circ} \mathrm{E}, 300^{\circ} \mathrm{E}(\mathrm{LT} 0,4,8,12,16,20 \mathrm{~h})$. 


\section{Trough model parameters}

We calculated the position of the trough minimum with the model A of Werner and Prölss (1995). For our additional calculations of the relative depth of the trough, the half widths equatorwards and polewards, the total width of the trough and the relative steepnesses (polewards and equatorwards) we decided to restrict modelling to Northern Hemisphere troughs. We used data from a satellite altitude $<700 \mathrm{~km}$ only, restricted the acceptable relative depth to $>20 \%$ and neglected troughs with a total width of more than 20 degrees in invariant latitude.

We calculated histograms and the most important quantiles of the distributions of trough parameter data under various conditions. Table I lists lower quartiles, medians and upper quartiles for the trough parameters used for modelling and fig. 2 shows graphics of a few selected histograms. The width of the trough was «measured» between the midpoints of the trough walls and split into an equatorward «half width» and a poleward one. The steepnesses also refer to the midpoints of the walls.

The trough model makes use of the medians of

- the relative depth;

- the half widths;

- the relative steepnesses.

After several tests with different formulations we settled on a composite. The trough now consists of two parts, the equatorward part and the poleward part. Both parts use ellipse sectors for bottom and top joined together by straight lines in such a way that the first derivatives are

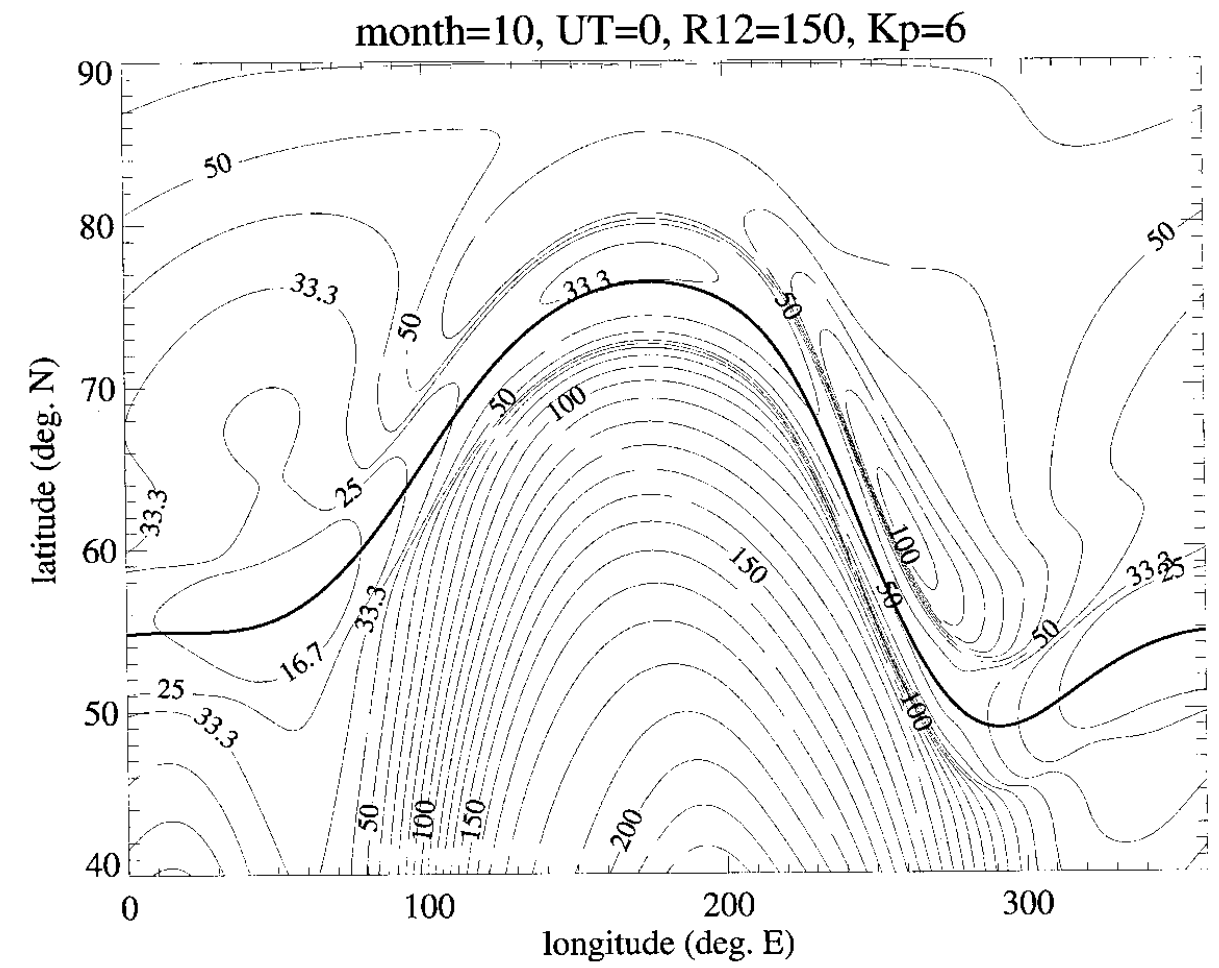

Fig. 4. Peak electron density from the ITU-R (CCIR) coefficients combined with the trough model. Contours of constant electron density in units of $10^{10} \mathrm{~m}^{-3}$ over a geographic coordinate system. $\mathrm{UT}=0 \mathrm{~h}, R_{12}=150, K_{p}=6$. Thick curve: position of the trough minimum. 
continuous. The equatorward and poleward parts meet at the trough minimum. The poleward part includes a $20 \%$ enhancement which fades out like a Gaussian.

The test trough formulations had disadvantages. The modified semi-Gaussians presented in Leitinger and Feichter (1999) resulted in troughs which were too «rectangular» in the cases of larger steepness.

Despite their low number in the DE 2 data we included «summer» trough properties in our model but the user should be aware that summer troughs are not as stable and reliable as winter and equinox troughs when the main trough is a normal feature of the ionosphere. Nighttime summer troughs (if they occur) usually have special properties: they have considerably smaller width and the equatorward walls are much steeper than the poleward walls.

For a global model it is necessary to have smooth transitions from «day» to «night» and from «night» to «day». We have ensured this by using exponentials in the following way:

$$
\begin{aligned}
& f(t)=\left\{\left(f_{1}(t) \exp \left[\alpha\left(t-t_{0}\right)\right]+\right.\right. \\
& \left.+f_{2}\right\} /\left\{1+\exp \left[\alpha\left(t-t_{0}\right)\right]\right\}
\end{aligned}
$$

( $t_{0}:$ mid-time of transition; $\alpha$ : steepness parameter; $f_{1}$ : function for $t>t_{0} ; f_{2}$ : function for $\left.t<t_{0}\right)$.
Figure 3 shows examples for the latitude dependence of the trough model combined with $F_{2}$ peak density derived from the ITU-R (formerly CCIR) coefficients for January 0 hours UT, high solar activity $\left(R_{12}=150\right)$, high level of geomagnetic activity $\left(K_{p}=6\right)$ and a selection of geographic longitudes. Figure 4 shows contours of constant peak electron density in a geographic coordinate system for the conditions of fig. 3 . The trough minimum is also shown.

\section{REFERENCES}

ANNAKUliEV, S.K., V.V. Afonin, M.G. DEMinOV and A.T. KARPACHEV (1997): Empirical formulae for the main ionospheric trough position during magnetic storm, Geomagn. Aeron., 37, 183-187.

LEITINGER, R. and E. FEICHTER (1999): Modelle für den Trog der F Schicht: Möglichkeiten und Grenzen, Kleinheubacher Berichte, 42, 63-70.

LETINGER, R., S. RADICELLA, E. FEICHTER and B. NAVA (2001): Electron density models suitable for assessment studies which involve satellite to ground and satellite to satellite electron content, in Proceedings Beacon Satellite Symposium 2001, edited by P. DOHERTY, on CR-ROM.

PUTZ, E. and R. LEITINGER (1988): A proposed model for the TEC main trough in Winter and Equinox nights, in Investigation of the Ionosphere by Means of Beacon Satellite Measurement, edited by CAO CHONG, (International Academic Publishers, Pergamon), 209- 216.

Werner, S. and G.W. PrölSS (1995): The position of the ionospheric trough - an empirical model based on DE 2 observations, Kleinheubacher Berichte, 38, 143-154. 